This item was submitted to Loughborough's Research Repository by the author.

Items in Figshare are protected by copyright, with all rights reserved, unless otherwise indicated.

\title{
Semipermeable elastic microcapsules for gas capture and sensing
}

PLEASE CITE THE PUBLISHED VERSION

http://dx.doi.org/10.1021/acs.langmuir.6b02420

PUBLISHER

(c) American Chemical Society

VERSION

AM (Accepted Manuscript)

\section{PUBLISHER STATEMENT}

This work is made available according to the conditions of the Creative Commons Attribution-NonCommercialNoDerivatives 4.0 International (CC BY-NC-ND 4.0) licence. Full details of this licence are available at: https://creativecommons.org/licenses/by-nc-nd/4.0/

\section{LICENCE}

CC BY-NC-ND 4.0

\section{REPOSITORY RECORD}

Nabavi, Ali, Goran Vladisavljevic, Sai Gu, and Vasilije Manovic. 2016. "Semipermeable Elastic Microcapsules for Gas Capture and Sensing”. Loughborough University. https://hdl.handle.net/2134/22593. 


\section{Semipermeable elastic microcapsules for gas capture and sensing}

Seyed Ali Nabavi, ${ }^{*, \neq, \dagger}$ Goran T. Vladisavljević, ${ }^{*,}$ Sai Gu, ${ }^{\wedge}$ Vasilije Manović ${ }^{\dagger}$

${ }^{\dagger}$ Combustion and CCS Centre, Cranfield University, Cranfield, MK43 0AL, United Kingdom.

${ }^{\ddagger}$ Department of Chemical Engineering, Loughborough University, Loughborough LE11 3TU, United Kingdom.

${ }^{\star}$ Department of Chemical and Process Engineering, University of Surrey, Guildford GU2 7XH, United Kingdom.

\section{Abstract}

Monodispersed microcapsules for gas capture and sensing were developed consisting of elastic semipermeable polymer shells of tuneable size and thickness and $\mathrm{pH}$-sensitive, gas selective liquid cores. The microcapsules were produced using glass capillary microfluidics and continuous on-the-fly photopolymerisation. The inner fluid was 5-30 wt $\% \mathrm{~K}_{2} \mathrm{CO}_{3}$ solution with m-cresol purple, the middle fluid was a UV-curable liquid silicon rubber containing 0-2 wt\% Dow Corning $^{\circledR} 749$ fluid, and the outer fluid was aqueous solution containing 60-70 wt\% glycerol and 0.5-2 wt\% stabiliser (polyvinyl alcohol, Tween 20 or Pluronic ${ }^{\circledR}$ F-127). An analytical model was developed and validated for prediction of the morphology of the capsules under osmotic stress based on the shell properties and the osmolarity of the storage and core solutions. The minimum energy density and UV light irradiance needed to achieve complete shell polymerisation were $2 \mathrm{~J} \cdot \mathrm{cm}^{-2}$ and $13.8 \mathrm{~mW} \cdot \mathrm{cm}^{-2}$, respectively. After UV exposure, the curing time for capsules containing 0.5 wt $\%$ Dow Corning ${ }^{\circledR} 749$ fluid in the middle phase was 
30-40 min. The $\mathrm{CO}_{2}$ capture capacity of $30 \mathrm{wt} \% \mathrm{~K}_{2} \mathrm{CO}_{3}$ capsules was $1.6-2 \mathrm{mmol} / \mathrm{g}$ depending on the capsule size and shell thickness. A cavitation bubble was observed in the core when the internal water was abruptly removed by capillary suction, whereas a gradual evaporation of internal water led to buckling of the shell. The shell was characterised using TGA, DSC, and FTIR. The shell degradation temperature was $450-460^{\circ} \mathrm{C}$.

KEYWORDS: Elastic microcapsules; Glass capillary microfluidics; Semipermeable shell membrane; On-the-fly photopolymerisation, $\mathrm{CO}_{2}$ capture; Osmotic imbalance; Capillaryinduced cavitation.

\section{INTRODUCTION}

Microencapsulation of fluids, including liquids and gases, within solid shell membranes has been of great interest for a wide variety of applications. The shell membranes can be classified as impermeable (dense) and semipermeable (porous). Impermeable membranes do not allow diffusion of any species into or out of the capsules. Microcapsules with impermeable membranes have been used for encapsulation of pigments for electrophoretic displays used in e-book readers such as the Amazon Kindle ${ }^{1,2}$ and for enhanced retention of fragrance ${ }^{3}$. Semipermeable membranes consisting of nanopores which allow the permeation of molecules smaller than the size of the pores while preventing the passage of larger ones, ${ }^{4}$ find numerous applications for controlled release of drugs, nutrients and nanoparticles, ${ }^{5-9}$ energy storage and photocatalysis, ${ }^{10}$ $\mathrm{CO}_{2}$ capture, ${ }^{11}$ biomolecular catalysis, ${ }^{12,13}$ and culture of stem cells ${ }^{14}$.

Conventional methods for fabrication of core-shell capsules such as complex coacervation, ${ }^{15}$ internal phase separation, ${ }^{16}$ layer-by-layer electrostatic deposition, ${ }^{17}$ interfacial polymerisation, ${ }^{18}$ and spray drying ${ }^{19}$ typically require multi-stage processing and do not allow precise control over 
the shell thickness and capsule size. In addition, the particles are usually polydispersed and suffer from low encapsulation efficiency. ${ }^{20}$

Microfluidic emulsification/polymerisation is a promising tool for production of core-shell capsules of tuneable size and shell thickness. Two main microfluidic strategies for production of core-shell drops are one-step drop formation process using a single drop maker ${ }^{21}$ and two-step drop formation process using two consecutive flow-focusing, ${ }^{22}$ T-junction, ${ }^{23}$ or co-flow ${ }^{24}$ drop makers. Utada et al. ${ }^{21}$ have developed a 3D glass capillary device that combines counter-current flow focusing and co-flow. The device is cheap, easy to fabricate, and provides precise control of the droplet size and shell thickness. In addition, the wettability of individual capillaries can be independently controlled and readily modified, ${ }^{25}$ which overcomes the wettability control problems found in polydimethylsiloxane (PDMS) devices. Core-shell drops can be formed in two distinct regimes, dripping and jetting. Dripping is the favourable mode of core-shell droplet generation since the droplets are highly uniform in size, while the jetting regime is associated with polydispersed droplet formation. ${ }^{26,27}$

Vericella et al. ${ }^{11}$ have developed liquid core-solid shell capsules for $\mathrm{CO}_{2}$ capture to address the drawbacks of traditional amine scrubbing while keeping all benefits of liquid absorbents, such as high $\mathrm{CO}_{2}$ capture capacity and selectivity. Amine scrubbing, mainly using monoethanolamine (MEA), is the most established and industrially proven approach for $\mathrm{CO}_{2}$ capture. However, MEA is corrosive and degrades during repeated regeneration cycles at elevated temperatures into the products that pose a hazard to human health and the environment. ${ }^{28,29}$ Encapsulation prevents evaporation of absorbent and its direct contact with the capture system, and provides much higher surface area-to-volume ratio, in comparison to typical packed towers. ${ }^{11}$ The capsules were produced using a two-step process consisting of generation of core-shell drops in a microfluidic 
device and subsequent shell polymerisation by exposing the collected drops to UV light in a vial. $^{11}$

However, a single step process that combines microfluidic drop generation and in-situ shell polymerisation in the collection channel is highly preferred for continuous production of capsules. In addition, although there are several studies on the effect of osmotic pressure imbalance on the stability of core-shell drops and capsules with hard shells, ${ }^{30-32}$ the effect is yet to be investigated for capsules with elastic shells, where the osmotic pressure gradient across the shell can dramatically change the morphology of the capsules and encapsulation efficiency.

In this work, a single-step process was developed for continuous production of capsules with elastic gas-permeable shells combining glass capillary microfluidic emulsification and on-the-fly photopolymerisation. The study aimed at encapsulating highly alkaline aqueous solutions in the presence of a pH-sensitive marker so that the saturation of capsules with $\mathrm{CO}_{2}$ can be visually detected. Several combinations of oil- and water- soluble stabilisers were tested over a wide range of concentrations to find the optimum formulation that will not lead to precipitation of the stabilisers due to high $\mathrm{pH}$ of the core solution. Several phenomena that can dramatically change the morphology and internal structure of the capsules have been observed such as swelling due to osmotic imbalance between core and storage solution, evaporation-induced buckling, and capillary pressure-triggered cavitation in the core. The cured shells were characterised using TGA, DSC, FTIR, and a very high thermal stability was observed. 


\section{EXPERIMENTAL PROCEDURE}

\section{Materials}

The inner phase was an aqueous solution containing 5-30 wt $\% \mathrm{~K}_{2} \mathrm{CO}_{3}$ (Fisher Scientific, UK) and a small amount of the $\mathrm{pH}$ indicator m-cresol purple (Sigma-Aldrich, UK). The middle phase was a UV-curable liquid silicon rubber (Semicosil ${ }^{\circledR}$ 949, Wacker Chemie, UK) containing 0-2 wt\% Dow Corning ${ }^{\circledR} 749$ Fluid (DC 749, Univar, UK) added as a lipophilic stabiliser. DC 749 is a blend consisting of approximately 50\% cyclomethicone (decamethylcyclopentasiloxane), a hydrophobic compound, and 50\% trimethylsiloxysilicate. Trimethylsiloxysilicate molecules contain three hydrophobic methyl groups at one end of the siloxane bond ( $\equiv \mathrm{Si}-\mathrm{O}-\mathrm{Si} \equiv)$ and three hydrophilic hydroxyl groups at the other end, causing DSC 749 to accumulate at the O/W interface and stabilise double emulsion drops. The outer phase was an aqueous solution containing 30-70 wt\% glycerol (Fisher Scientific, UK) and 0-2 wt\% hydrophilic stabiliser (polyvinyl alcohol (PVA), Tween 20 or Pluronic ${ }^{\circledR}$ F-127 (PF-127), Sigma-Aldrich, UK). The reverse osmosis water was supplied using a Milli-Q plus apparatus.

\section{Microcapsule generation}

Fabrication of glass capillary microfluidic device: The round glass capillaries with I.D. and O.D. of 0.58 and $1 \mathrm{~mm}$, respectively (Intracel, UK), were pulled in a Flaming/Brown micropipette puller (P-97, Sutter Instrument Co., Linton Instrumentation, Norfolk, UK) to produce the tapered tips for injection and collection capillaries. The tips were then polished to the desired orifice size using an abrasive paper (Black Ice Waterproof T402 Paper, Alpine Abrasives, UK), which was checked under a microforge microscope (Narishige MF-830, Japan). Octadecyltrimethoxysilane and 2-[methoxy(polyethyleneoxy)propyl]trimethoxysilane were used to make the capillary tips hydrophobic and hydrophilic, respectively. The injection and collection capillaries were inserted into a square glass capillary with an inner width of $1.05 \pm 0.1 \mathrm{~mm}$ (AIT 
Glass, Rockaway, US), placed at a desired distance of each other and axially centred using an inverted microscope (XDS-3, GX Microscopes, UK). The two-part epoxy glue (5-Minute Epoxy ${ }^{\circledR}$ Devcon) was used to fix the capillaries into position on a microscope slide. Three hypodermic needles with polypropylene hubs (BD Precisionglide ${ }^{\circledR} 20$ G, Sigma-Aldrich, UK) were attached on the capillaries, using the epoxy glue, to introduce the three phases to the device (Figure 1). The device was left 4-5 $\mathrm{h}$ before use to ensure the glue was fully cured.

Double emulsion formation: A schematic of the experimental setup is shown in Figure 1. Three gastight glass syringes with Luer-lock fitting (VWR Catalyst Company, UK) were filled with the three phases and placed on Harvard Apparatus 11 Elite syringe pumps. Polyethylene medical tubing with $0.86 \mathrm{~mm}$ I.D. and $1.52 \mathrm{~mm}$ O.D (Fisher Scientific, UK) was used to deliver the three phases into the device. Core-shell drops were formed upon break-up of coaxial jet of two coflowing liquids (the inner and middle phase) into the collection tube. An inverted microscope and Phantom V9.0 high-speed camera interfaced to a PC computer were used to monitor the drop formation process in real time. The ImageJ software was used to analyse the captured frames.

Shell polymerisation: The photopolymerisation of the shell was initiated by exposing the drops to UV-A radiation of $0.7-38.1 \mathrm{~mW} \cdot \mathrm{cm}^{-2}$ downstream of the device. After exposure to UV light, the drops were collected in a storage solution to be fully cured. During exposure to UV light, the microfluidic device, syringes, and all the tubing, except the collection tube were covered by aluminium foil to prevent premature polymerisation of the middle phase. 


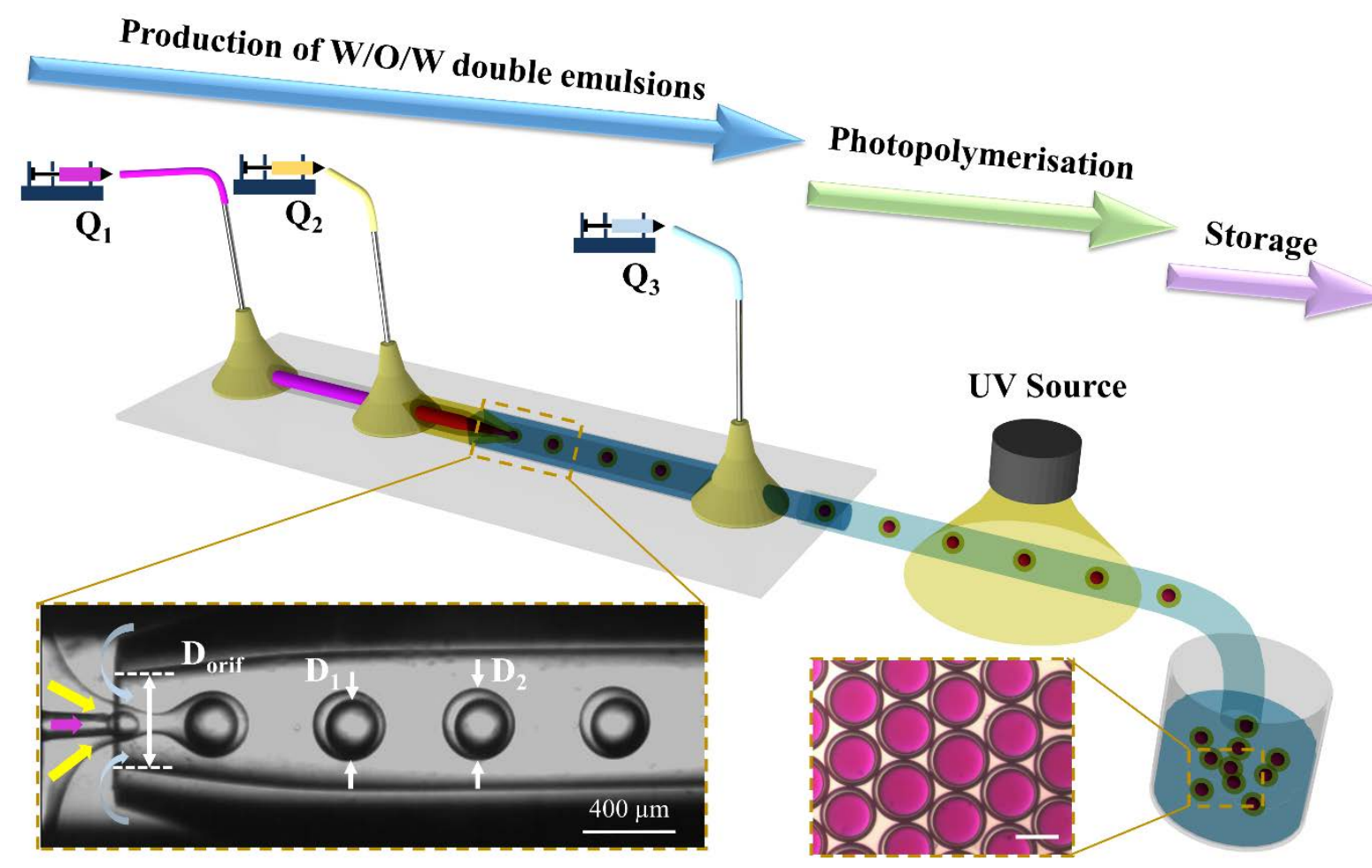

Figure 1. Schematic of the experimental set-up consisting of a glass capillary device, three syringe pumps and a UV-A source for on-the-fly in-situ photopolymerisation of the shells. The scale bar on the capsules image is $400 \mu \mathrm{m}\left(\mathrm{D}_{1}, \mathrm{D}_{2}, \mathrm{D}_{\text {orif }}\right.$ - diameter of inner drops, outer drops and orifice; $\mathrm{Q}_{1}, \mathrm{Q}_{2}, \mathrm{Q}_{3}$ - volumetric flow rate of inner, middle and outer phase).

\section{Material characterisation}

Thermal gravimetric analysis (TGA). The thermal stability of the membrane shell prepared using different concentrations of the lipophilic surfactant DC 749 was characterised using a thermogravimetric analyser (TGA) Q5000IR (TA Instruments, US) under a nitrogen flow rate of $20 \mathrm{~mL} / \mathrm{min}$ by heating $10-20 \mathrm{mg}$ of capsules from 50 to $600^{\circ} \mathrm{C}$ at a ramp rate of $10^{\circ} \mathrm{C} / \mathrm{min}$.

Fourier transform infrared (FTIR) spectroscopy. The FTIR spectra of the shell membranes were measured over the range of 500-4000 $\mathrm{cm}^{-1}$ using a Thermo Scientific Nicolet iS50 ATR spectrometer with a monolithic diamond crystal. The samples were placed on the Universal diamond ATR top-plate and the spectrum was recorded within $32 \mathrm{~s}$. 
Differential scanning calorimetry (DSC). Modulated Differential Scanning Calorimetry (DSC) analysis was done using a TA Instruments Model 2910 calorimeter. 5-10 mg of the sample was placed in an aluminium pan and hermetically sealed. The sample pan was heated from 50 to $290^{\circ} \mathrm{C}$ at a ramp rate of $10^{\circ} \mathrm{C} / \mathrm{min}$ and the difference in heat flow between the sample and empty pan was measured. Dry nitrogen at $60 \mathrm{~mL} / \mathrm{min}$ was used as the purge gas.

Scanning Electron Microscopy (SEM). The morphology of cross-sectioned capsules after curing was analysed using a TM3030 bench-top scanning electron microscope (Hitachi, Tabletop Microscope Europe) operating at an accelerating voltage of $15 \mathrm{keV}$. Prior to SEM, the capsules were cross-sectioned into $10 \mu \mathrm{m}$ sections with a cryotome (MSE) equipped with a glass knife. The cross-sectioned capsules were coated with gold/palladium (80/20) prior to the SEM to prevent accumulation of electrostatic charges on the particles. The sputtering rate was $0.85 \mathrm{~nm}$ per second at $2 \mathrm{kV}$ and $25 \mathrm{~mA}$ of plasma current.

\section{RESULTS AND DISCUSSION}

\section{Production of double emulsion drops and their stability}

Since the viscosity of the middle phase was very high (200 mPa·s), a highly viscous outer phase was used to achieve a pinch-off of compound jet in dripping mode. The concentration of glycerol in the outer phase of $60-70 \mathrm{wt} \%$ was found to provide the optimal shear force to generate highly uniform double emulsion drops close to the orifice of the collection capillary. A further increase in the glycerol concentration tended to suppress flow of the middle phase into the collection capillary, which caused rupture of the middle phase layer and release of the inner fluid into the outer phase. 
In the absence of any lipophilic stabiliser in the middle phase, the produced core-shell drops were unstable and the inner drops were released shortly after drop collection. The addition of DC 749 in the middle (oil) phase considerably increased the stability of core-shell drops before shell polymerisation. In these experiments, the middle phase contained $0,0.5$, or $2 \mathrm{wt} \% \mathrm{DC} 749$, the outer fluid was an aqueous solution containing $70 \mathrm{wt} \%$ glycerol and $2 \mathrm{wt} \%$ PVA, and the inner phase was $5 \mathrm{wt} \% \mathrm{~K}_{2} \mathrm{CO}_{3}$ and m-cresol purple dissolved in deionised water. The produced drops were collected in an aqueous solution containing 1-2 wt\% PVA. The drops prepared without any lipophilic stabiliser were stable for $15-20$ min, those stabilised with 0.5 wt\% DC 749 were stable for 30-40 min, whereas the drops stabilised with $2 \mathrm{wt} \%$ DC 749 were stable for several months.

When the drops were collected in $0.5-1$ wt $\%$ PF-127 instead of 1-2 wt\% PVA, the stability of the drops containing $0.5 \mathrm{wt} \%$ DC 749 in the middle phase increased from $30-40$ min to more than one hour. However, in the absence of any lipophilic stabiliser, the difference in performance between the two hydrophilic stabilisers was negligible. In addition, there was no noticeable difference in performance between 0.5 wt\% PF-127 and 1 wt\% PF-127. Therefore, either 0.5 or $1 \mathrm{wt} \%$ PF-127 provided sufficient stability to the collected drops until they were fully cured.

The $\mathrm{pH}$ of the inner phase can significantly affect the stability of double emulsion drops. ${ }^{32}$ Ideally, the inner and outer fluids do not come into contact during core-shell drop generation. However, during start-up the inner and outer aqueous phase are inevitably in contact with each other in the injection capillary and there might occasionally be some interruptions of the drop formation process, which may cause the inner phase to flow into the outer phase. Once the two phases are in direct contact, the high $\mathrm{pH}$ of the inner phase can cause the hydrolysis of acetate groups in PVA molecules. It was found that PVA grades with high degrees of hydrolysis have low solubility in water, since the absence of hydrophobic acetate groups strengthens the intra- 
and intermolecular hydrogen bonding between hydroxyl groups, thereby promoting aggregation and sedimentation of PVA molecules. ${ }^{33}$ For double emulsions containing $5 \mathrm{wt} \%$ and $15 \mathrm{wt} \%$ $\mathrm{K}_{2} \mathrm{CO}_{3}$ in the inner phase, with a pH of 11.9 and 12.2 respectively, all the stabilisers used in the outer phase (0.5-2 wt\% PVA, 0.5-2 wt\% Tween 20, and 0.5-1 wt\% PF-127) were capable of stabilising the drops without any fouling problems. However, for the emulsions containing 30 wt $\% \mathrm{~K}_{2} \mathrm{CO}_{3}$ in the inner phase and 0.5-2 wt\% PVA in the outer phase, due to high $\mathrm{pH}$ of the inner phase of 12.7, significant sedimentation of PVA occurred, which resulted in clogging of the injection capillary. The same behaviour was observed when $1 \mathrm{wt} \%$ PF-127 was used. For Tween 20, owing to its low molecular weight and high solubility in water, no sedimentation or clogging occurred, but most of the shells collapsed within the collection tube shortly after drop formation. Decreasing the PF-127 concentration in the outer phase from 1 to $0.5 \mathrm{wt} \%$ highly improved the stability of drop formation process with $30 \mathrm{wt} \% \mathrm{~K}_{2} \mathrm{CO}_{3}$ in the inner phase and no sedimentation was observed within the device after one hour of production. Therefore, $0.5 \mathrm{wt} \%$ PF-127 was the optimum stabiliser in the outer phase for a highly alkaline inner phase. 


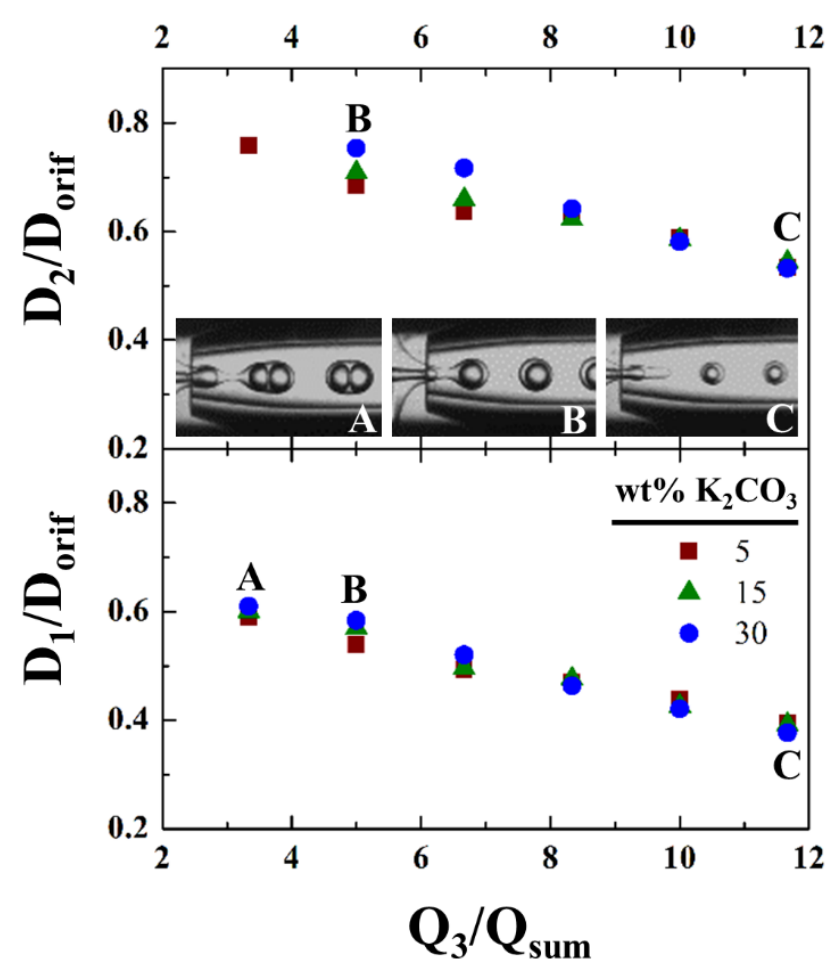

Figure 2. Effect of outer phase flow rate, $\mathrm{Q}_{3}$, on the inner and outer droplet diameter, $\mathrm{D}_{1}$ and $D_{2}$. The orifice size of the injection and collection capillary ( $D_{\text {orif }}$ ) was 50 and $430 \mu \mathrm{m}$, respectively. The distance between the two capillaries was $48 \mu \mathrm{m}$. $\mathrm{Q}_{1}=\mathrm{Q}_{2}=1.5 \mathrm{~mL} / \mathrm{h}$, $\mathrm{Q}_{\text {sum }}=\mathrm{Q}_{1}+\mathrm{Q}_{2}$. The images $\mathrm{A}, \mathrm{B}$, and $\mathrm{C}$ show formation of double emulsion drops containing $30 \mathrm{wt} \% \mathrm{~K}_{2} \mathrm{CO}_{3}$ in the inner phase at $\mathrm{Q}_{3}=10,15$, and $35 \mathrm{~mL} / \mathrm{h}$, respectively.

Figure 2 shows the effect of outer phase flow rate on the diameter of inner and outer drops, $\mathrm{D}_{1}$ and $\mathrm{D}_{2}$. The outer diameter and the shell thickness were controlled in the range of 200-400 and 20-30 $\mu \mathrm{m}$, respectively, by changing the flow rate of the three fluid streams and the coefficient of variation of droplet diameters was less than 2.6\%. By increasing the outer phase flow rate from 5 to $35 \mathrm{~mL} / \mathrm{h}$ at the constant inner and middle phase flow rates of $1.5 \mathrm{~mL} / \mathrm{h}$, the droplet size was reduced from 324 to $228 \mu \mathrm{m}$, while the shell thickness remained unchanged at $30 \mu \mathrm{m}$. The same behaviour was predicted numerically by Nabavi et al. ${ }^{26}$ An increase in the concentration of $\mathrm{K}_{2} \mathrm{CO}_{3}$ in the core solution from 5 to $30 \mathrm{wt} \%$ at the outer phase flow rate of $5-10 \mathrm{~mL} / \mathrm{h}$ caused a slight increase in the droplet diameter which could be attributed to the higher viscosity of the compound jet formed in the collection tube and its higher resistance to pinch-off. With further 
increase of the outer phase flow rate above $35 \mathrm{~mL} / \mathrm{h}$, the diameter of the compound jet at the exit of the injection capillary became equal to the diameter of the injection nozzle, which caused the inner phase to rupture the middle phase and the droplet formation was interrupted. Reducing the outer phase flow rate to less than $5 \mathrm{~mL} / \mathrm{h}$ resulted in the formation of multi-cored double emulsion droplets, as shown in Figure 2a.

\section{Optimisation of shell photo-polymerisation}
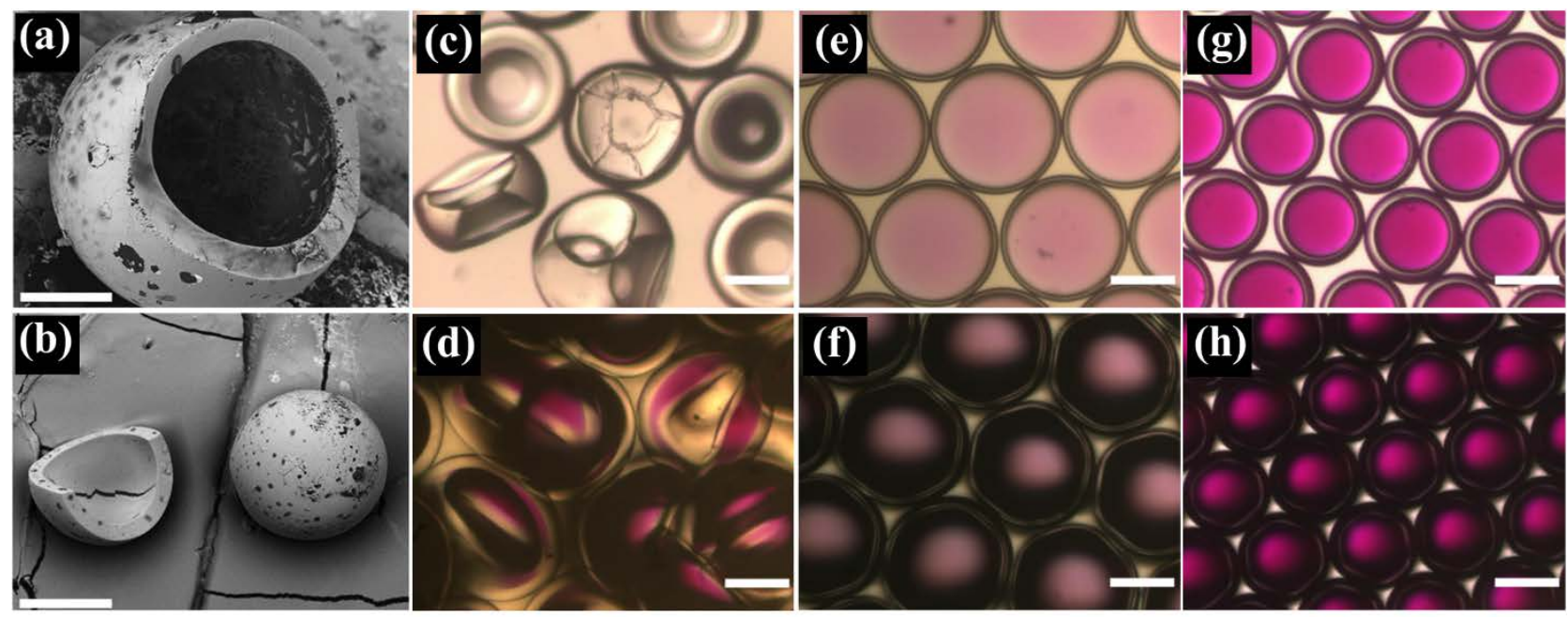

Figure 3. (a \& b) SEM images of microtome cross-sectioned capsules prepared under optimal conditions; (c) collapsed capsules synthesised without DC 749 in the middle phase; (d) dehydrated buckled capsules with $15 \mathrm{wt} \% \mathrm{~K}_{2} \mathrm{CO}_{3}$ in the core after $6 \mathrm{~h}$ of exposure to ambient air; (e) $15 \mathrm{wt} \%$ $\mathrm{K}_{2} \mathrm{CO}_{3}$ capsules before capillary-induced cavitation; (f) $15 \mathrm{wt} \% \mathrm{~K}_{2} \mathrm{CO}_{3}$ capsules with cavitationformed vapour bubble; (g) $5 \mathrm{wt} \% \mathrm{~K}_{2} \mathrm{CO}_{3}$ capsules before capillary-induced cavitation; (h) $5 \mathrm{wt} \%$ $\mathrm{K}_{2} \mathrm{CO}_{3}$ capsules with cavitation-formed vapour bubble. The scale bars: (a) $100 \mu \mathrm{m}$; (b-h) $200 \mu \mathrm{m}$.

In this work, two different methods of UV exposure were used. In the first method, only the collection vial was exposed to UV light and other parts were covered by aluminium foil ("semibatch photopolymerisation”). In the second method, only a specific length of the collection tube, $\mathrm{L}_{\text {exp }}$, was exposed to UV light (“continuous on-the-fly photopolymerisation”). For a successful photopolymerisation, UV irradiance and exposure time must be carefully controlled. In this 
work, two different UV sources were used: a low-intensity UV-A system consisting of five $4 \mathrm{~W}$ UV-A back light tubes and a $250 \mathrm{~W}$ Hoenle UVAHAND 250 Mobile UV lamp. The UV light irradiance on the sample was monitored using a Cole-Parmer radiometer and was varied from 0.7 to $38.1 \mathrm{~mW} \cdot \mathrm{cm}^{-2}$ by adjusting the distance between the UV lamp and sample, $\mathrm{L}_{\mathrm{uv}}$ (Table 1 ).

In the first method, UV exposure time was independent of the flow rate in the collection tube since the drops were exposed to UV light after collection. In these experiments, the collection vial was exposed to UV-A radiation for $1-10 \mathrm{~min}$ at $13.8-38.1 \mathrm{~mW} \cdot \mathrm{cm}^{-2}$ or for $1 \mathrm{~min}$ to $12 \mathrm{~h}$ at 0.7-3.05 $\mathrm{mW} \cdot \mathrm{cm}^{-2}$. In the majority of the capsules produced using this approach, the shell was not entirely solidified causing leakage of the inner solution, or the fabricated capsules were highly fragile. Figure s.2b shows leakage of the marker dye from the capsules after one hour of production, when the collection vial was exposed to UV light at $38.1 \mathrm{~mW} \cdot \mathrm{cm}^{-2}$ for $6 \mathrm{~min}$. This might be caused by reduction of the intensity of UV light as it passed through the collection solution. In addition, it was noticed that for the irradiance in the range of $13.8-38.1 \mathrm{~mW} \cdot \mathrm{cm}^{-2}$, exposure times over 6 min resulted in the overexposure effect and degradation of cured capsules.

The second method involved on-the-fly in-situ photopolymerisation and the main objective of these experiments was to determine the minimum UV light irradiance and exposure time needed to achieve complete shell polymerisation without overexposure effects. The exposure time, $t_{r}$ was calculated as $\mathrm{V}_{\text {tube }} / \mathrm{Q}_{\text {total }}$, where $\mathrm{Q}_{\text {total }}=\mathrm{Q}_{1}+\mathrm{Q}_{2}+\mathrm{Q}_{3}$ and $\mathrm{V}_{\text {tube }}$ is the volume of collection tube exposed to UV light. The energy density $\left(\mathrm{J} \cdot \mathrm{cm}^{-2}\right)$ of $U V$ light was calculated as $E_{u v}=I_{u v} t_{r}$, where $\mathrm{I}_{\mathrm{uv}}\left(\mathrm{mW} \cdot \mathrm{cm}^{-2}\right)$ is the irradiance. The middle phase was $0.5 \mathrm{wt} \%$ DC 749 in Semicosil ${ }^{\circledR}$ 949, the inner phase was $15 \mathrm{wt} \% \mathrm{~K}_{2} \mathrm{CO}_{3}$ solution and the irradiated droplets were collected in a $1 \mathrm{wt} \%$ aqueous solution of PVA. The total flow rate in the collection tube, $\mathrm{Q}_{\text {total }}$ was $19.6 \mathrm{~mL} / \mathrm{h}$, and $25 \mathrm{~cm}$ of the collection tube was irradiated resulting in an exposure time of $144 \mathrm{~s}$. It was 
found that UV light irradiance of 13.8-38.1 $\mathrm{mW} \cdot \mathrm{cm}^{-2}$, corresponding to the energy density of 2$5.5 \mathrm{~J} \cdot \mathrm{cm}^{-2}$, resulted in successful polymerisation of the shell. The time needed for the shell to become fully cured after UV irradiation was 30-40 min. Owing to their elasticity, the synthesised capsules were mechanically robust and stable against bursting under a mild compressive force. The integrity of the shells after solidification was confirmed by SEM images of cross-sectioned capsules in Figures 3a and 3b.

In contrast, the shells produced from the drops irradiated with less than $13.8 \mathrm{~mW} \cdot \mathrm{cm}^{-2}$ were very fragile and easily collapsed. To determine the minimum energy density needed for activation of the initiator at the irradiance of $13.8 \mathrm{~mW} \cdot \mathrm{cm}^{-2}$, the exposed length of the collection tube was reduced from 25 to $15 \mathrm{~cm}$, which resulted in a shorter exposure time of $86 \mathrm{~s}$ and lower energy density of $1.2 \mathrm{~J} \cdot \mathrm{cm}^{-2}$ (Table 2). The capsules produced under these conditions were very fragile, implying that the energy of incident UV light was insufficient to activate the initiator. Therefore, the minimum energy density needed to initiate the shell polymerisation was $2 \mathrm{~J} \cdot \mathrm{cm}^{-2}$.

Table 1. The distance $\mathrm{L}_{\mathrm{uv}}$ between the UV source and sample, the UV light irradiance, $\mathrm{I}_{\mathrm{uv}}$, and the energy density, $\mathrm{E}_{\mathrm{uv}}$ for successful shell polymerisation (shaded area). The exposed length of the collection tube, $\mathrm{L}_{\exp }=25 \mathrm{~cm}$. Outer phase: $70 \mathrm{wt} \%$ glycerol and $1 \mathrm{wt} \% \mathrm{PF}-127$ in water; Middle phase: $0.5 \mathrm{wt} \%$ DC 749 in Semicosil ${ }^{\circledR}$ 949; Inner phase: $15 \mathrm{wt} \% \mathrm{~K}_{2} \mathrm{CO}_{3}$ and m-cresol purple in water; Collection solution: $1 \mathrm{wt} \%$ PVA in water, covered by aluminium foil. $\mathrm{Q}_{1}=2$ $\mathrm{mL} / \mathrm{h}, \mathrm{Q}_{2}=1.6 \mathrm{~mL} / \mathrm{h}$, and $\mathrm{Q}_{3}=16 \mathrm{~mL} / \mathrm{h}$.

\begin{tabular}{lccccc}
\hline & \multicolumn{2}{c}{ Successful polymerisation } & \multicolumn{2}{c}{$\begin{array}{c}\text { Unsuccessful } \\
\text { polymerisation }\end{array}$} \\
\hline $\mathbf{L}_{\mathbf{u v}}(\mathbf{c m})$ & 5 & 10 & 15 & 18 & 20 \\
$\mathbf{I}_{\mathbf{u v}}\left(\mathbf{m W} \cdot \mathbf{c m}^{-2}\right)$ & 38.1 & 20.3 & 13.8 & 10.8 & 9.1 \\
$\mathbf{E}_{\mathbf{u v}}\left(\mathbf{J} \cdot \mathbf{c m}^{-2}\right)$ & 5.5 & 2.9 & 2 & 1.5 & 1.3 \\
\hline
\end{tabular}


Table 2. Optimisation of the UV light exposure time, $\mathrm{t}_{\mathrm{r}}$ at the constant distance between the UV light source and collection tube, $\mathrm{L}_{\mathrm{uv}}=15 \mathrm{~cm}$. Successful shell polymerisation is shaded. Outer phase: 70 wt\% glycerol and 1 wt\% PF-127 in water; Middle phase: Semicosil ${ }^{\circledR} 949$ containing different amounts of DC 749; Inner phase: $15 \mathrm{wt} \% \mathrm{~K}_{2} \mathrm{CO}_{3}$ and m-cresol in water; Collection solution: $1 \mathrm{wt} \%$ PVA in water, covered by aluminium foil. $\mathrm{Q}_{\text {total }}=\mathrm{Q}_{3}+\mathrm{Q}_{2}+\mathrm{Q}_{1}$.

\begin{tabular}{|c|c|c|c|c|c|c|c|c|c|}
\hline \multirow{2}{*}{$\begin{array}{l}L_{\text {exp }} \\
(\mathrm{cm})\end{array}$} & \multicolumn{3}{|c|}{ No stabiliser } & \multicolumn{3}{|c|}{0.5 wt \% DC 749} & \multicolumn{3}{|c|}{2 wt \%DC 749} \\
\hline & $\begin{array}{c}Q_{\text {total }} \\
(\mathrm{mL} / \mathrm{h})\end{array}$ & $t_{r}(s)$ & $\frac{E_{u v}}{\left(J \cdot \mathbf{c m}^{-2}\right)}$ & $\begin{array}{c}Q_{\text {total }} \\
(\mathrm{mL} / \mathrm{h})\end{array}$ & $\begin{array}{c}t_{r} \\
(s)\end{array}$ & $\frac{E_{u v}}{\left(J \cdot \mathbf{c m}^{-2}\right)}$ & $\begin{array}{c}Q_{\text {total }} \\
(\mathrm{mL} / \mathrm{h})\end{array}$ & $t_{\mathrm{r}}(\mathrm{s})$ & $\underset{\left(\mathrm{J} \cdot \mathbf{c m}^{-2}\right)}{E_{u v}}$ \\
\hline 15 & 13.2 & 128 & 1.8 & 19.6 & 86 & 1.2 & 17.6 & 96 & 1.3 \\
\hline 25 & 13.2 & 214 & 3 & 19.6 & 144 & 2 & 17.6 & 160 & 2.2 \\
\hline
\end{tabular}

The effect of the amount of DC 749 in the middle phase on the on-the-fly photopolymerisation of the shell is summarised in Table 2. The power per unit area received from UV light was kept constant at $13.8 \mathrm{~mW} \cdot \mathrm{cm}^{-2}$ and two different lengths of the collection tube, 15 and $25 \mathrm{~cm}$, were exposed to UV light. For the middle phase without DC 749 and energy densities of 1.8 and 3 $\mathrm{J} \cdot \mathrm{cm}^{-2}$, corresponding to $\mathrm{t}_{\mathrm{r}}$ values of 128 and $214 \mathrm{~s}$, respectively, although the majority of the produced capsules were sufficiently robust, some of the shells collapsed before solidification (Figure 3c). This can be attributed to the low stability of the emulsion due to the absence of any lipophilic stabiliser. However, once the drops were exposed to UV light, the emulsion stability in the collection vial was improved. As mentioned above, without UV irradiation, all drops prepared without lipophilic stabiliser collapsed within 15-20 min, whereas after UV exposure, the majority of the drops survived the curing process lasted 30-40 min. The core-shell drops with $2 \mathrm{wt} \%$ DC 749 in the middle phase, exposed to $1.3 \mathrm{~mW} \cdot \mathrm{cm}^{-2}$ for $96 \mathrm{~s}$, resulted in fragile capsules, because the initiator was not fully activated at $E_{u v}<2 \mathrm{~mW} \cdot \mathrm{cm}^{-2}$. By increasing $\mathrm{t}_{\mathrm{r}}$ to $160 \mathrm{~s}$ and $\mathrm{E}_{\mathrm{uv}}$ to $2.2 \mathrm{~mW} \cdot \mathrm{cm}^{-2}$, full shell polymerisation was achieved, but the required curing time was longer than 60 min. This might be due to absorption of UV light by the stabiliser in the shell, which could reduce the amount of energy received by the initiator. This UV-protective 
effect of DC 749 could result in a lower rate of decomposition of the initiator, which might lead to longer polymerisation time.

\section{Effect of osmotic imbalance on the morphology of capsules}

The effect of the osmotic pressure gradient across the shell on the morphology of the capsules was also investigated. Since the shell was permeable to water and impermeable to $\mathrm{K}^{+}$and $\mathrm{HCO}_{3}{ }^{-}$ ions, based on the osmolarity difference between the core and storage solution, the capsules lost or gained water when placed in hypertonic or hypotonic solutions, respectively. This osmotic imbalance resulted in variable size of the capsules, caused by the shell elasticity and build-up of positive or negative pressure in the core solution.

Figures 4a-d illustrate the effect of $\mathrm{K}_{2} \mathrm{CO}_{3}$ concentration in the storage solution on the size of the capsules containing $15 \mathrm{wt} \% \mathrm{~K}_{2} \mathrm{CO}_{3}$ solution in the core. The capsules placed in a $15 \mathrm{wt} \%$ $\mathrm{K}_{2} \mathrm{CO}_{3}$ solution did not experience any change in their size (Figure 4d), due to identical osmotic pressure on both sides of the shell. However, when the same capsules were placed in pure water, their size increased 2.7 times and the shell became thinner, as shown in Figure 4a. The fact that the capsules were significantly swollen in pure water proves that the shell was capable of retaining salt ions. Further evidence of negligible shell permeability to $\mathrm{K}_{2} \mathrm{CO}_{3}$ is provided in Supplementary material S5. In order to estimate the equilibrium capsule size, $\mathrm{D}_{2 \text {,eq }}$ in solutions of different osmolarities, a theoretical model was developed (see the supplementary material S1). The equilibrium size of the inner core, $\mathrm{D}_{1, \text { eq }}$ can be estimated by solving the following equation for $\beta$ :

$$
\left(\mathrm{KC}_{\text {out }}\right) \beta^{4}+\left(1-\mathrm{KC}_{\text {in }}\right) \beta-1=0
$$


where $\beta=D_{1, \text { eq }} / D_{1}$ is the expansion ratio of the core at equilibrium, $C_{\text {out }}$ and $C_{\text {in }}$ are the initial molarity of the storage solution and inner phase, respectively, and $\mathrm{K}$ is a constant based on the initial inner diameter, initial shell thickness, elastic modulus of the shell material, van 't Hoff factor, and temperature, Eq. (s.1.11). Also, $\mathrm{D}_{2, \mathrm{eq}}=\mathrm{D}_{1, \mathrm{eq}}+2 \mathrm{t}_{\mathrm{eq}}$, where $\mathrm{t}_{\mathrm{eq}}$ is the shell thickness at equilibrium, which can be calculated from Eq. (s.1.7). To validate the model, three samples of the capsules were prepared containing 5,15 , and $30 \mathrm{wt} \% \mathrm{~K}_{2} \mathrm{CO}_{3}$ solution in the core and stored in solutions of different osmolarities. The osmolarity of the storage solution was controlled by changing the concentration of $\mathrm{K}_{2} \mathrm{CO}_{3}$ in the range of $0-30 \mathrm{wt} \%$. The capsule size was measured after several days of storage to allow equilibrium to be established. The agreement between the experimental and theoretical values of $\mathrm{D}_{2 \text {,eq }}$ was very good, as shown in Figures $4 \mathrm{e}$-g, indicating high accuracy of the model to predict the capsule size in different storage solutions. The model was not able to predict the capsule size in pure water. The model is based on Hooke's law, which is only valid only if stress is proportional to strain. The model was unable to predict the capsule size in pure water because the yield strength of the shell material was exceeded due to excessive osmotic pressure gradient across the shell and the Hooke's low was no longer valid. However, the predicted capsule size in $0.25 \mathrm{wt} \% \mathrm{~K}_{2} \mathrm{CO}_{3}$ solution was very close to the experimental capsule size in pure water.

The capsules with $30 \mathrm{wt} \% \mathrm{~K}_{2} \mathrm{CO}_{3}$ solution in the core stored in pure water experienced the highest osmotic pressure gradient across the shell, which resulted in an equilibrium capsule size, $D_{2, \text { eq }}$ which was almost 4 times larger than the initial capsule size, $D_{2}$, and some shells ruptured due to excessive osmotic pressure stress. In addition, the surviving capsules were very fragile due to extremely thin shells of $\sim 2 \mu \mathrm{m}$, and burst by exerting a mild compressive force on them. The molarity of the inner phase at equilibrium, $\mathrm{M}_{\mathrm{in} \text {,eq }}$ was reduced by a factor of $\beta^{3}$ due to 
expansion of the core, where $\beta$ was found to be 5.6. Therefore, the concentration of $\mathrm{K}_{2} \mathrm{CO}_{3}$ in the core was reduced 176 times, which resulted in a significant reduction in the amount of $\mathrm{CO}_{2}$ that could be captured per unit mass of material. Apart from $30 \mathrm{wt} \% \mathrm{~K}_{2} \mathrm{CO}_{3}$ capsules stored in pure water, the remaining capsules survived the osmotic stress and no shell burst was observed. As shown in Figure 4g, the capsules with $5 \mathrm{wt} \% \mathrm{~K}_{2} \mathrm{CO}_{3}$ in the core stored in $8 \mathrm{wt} \%$ and $15 \mathrm{wt} \%$ $\mathrm{K}_{2} \mathrm{CO}_{3}$ have shrunk in diameter only by $0.6 \%$ and $1.4 \%$, respectively. The ability of the capsules to retain their size in hypertonic solutions can be attributed to low compressibility of the shell material. As shown in Figures 4e-g, the swelling of capsules in storage solutions containing less than $5 \mathrm{wt} \% \mathrm{~K}_{2} \mathrm{CO}_{3}$ was considerable for all cases, especially for $30 \mathrm{wt} \% \mathrm{~K}_{2} \mathrm{CO}_{3}$ in the core solution, leading to a shell thinning and a dilution of $\mathrm{K}_{2} \mathrm{CO}_{3}$ in the core. In addition, the capsules kept in $1 \mathrm{wt} \%$ PVA solution were just slightly larger than those stored in $5 \mathrm{wt} \% \mathrm{~K}_{2} \mathrm{CO}_{3}$ solution. Therefore, it is recommended to store the capsules in aqueous solutions containing $1 \mathrm{wt} \%$ PVA or not less than $5 \mathrm{wt} \% \mathrm{~K}_{2} \mathrm{CO}_{3}$. 

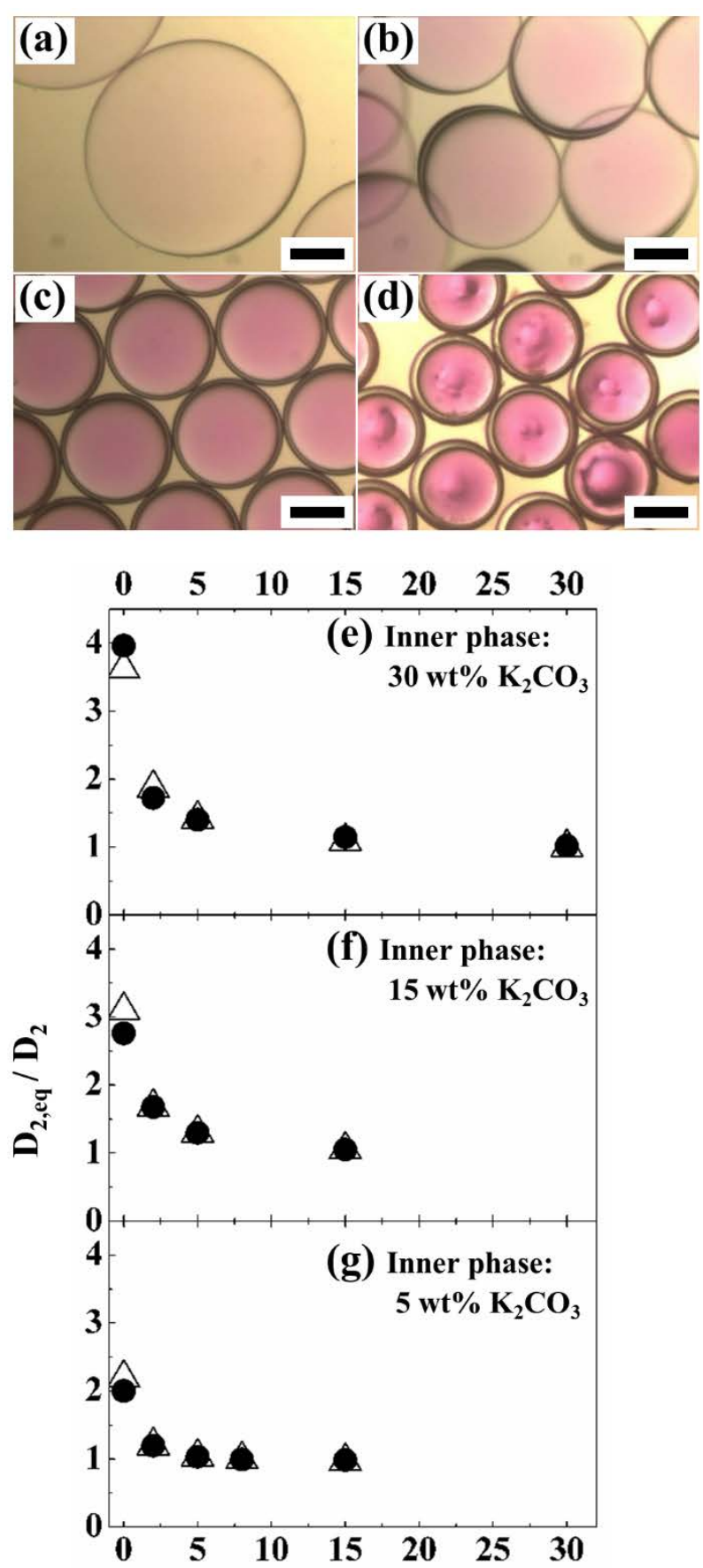

\section{Outer phase $\mathrm{K}_{2} \mathrm{CO}_{3}$ concentration (wt\%)}

Figure 4. (a-d) Optical images of capsules containing $15 \mathrm{wt} \% \mathrm{~K}_{2} \mathrm{CO}_{3}$ in the core and placed in different aqueous environments: (a) pure water; (b) $2 \mathrm{wt} \% \mathrm{~K}_{2} \mathrm{CO}_{3}$; (c) $5 \mathrm{wt} \% \mathrm{~K}_{2} \mathrm{CO}_{3}$; (d) $15 \mathrm{wt} \% \mathrm{~K}_{2} \mathrm{CO}_{3}$. All scale bars are $200 \mu \mathrm{m}$. (e-g) Comparison of experimental and theoretical predictions for the equilibrium expansion ratio, $\mathrm{D}_{2 \text {,eq }} / \mathrm{D}_{2}$, of the capsules in different environments. The $\mathrm{K}_{2} \mathrm{CO}_{3}$ concentration in the core: (e) $30 \mathrm{wt} \%$; (f) $15 \mathrm{wt} \%$; (g) $5 \mathrm{wt} \%$. $\mathbf{0}=$ experimental data, $\triangle=$ data calculated using the analytical model presented in the supplement S1. 
Figure 3d shows the capsules with 15 wt $\% \mathrm{~K}_{2} \mathrm{CO}_{3}$ in the core placed on a microscope slide and exposed to ambient air. Under these conditions, internal water gradually evaporated from the core, causing dehydration of the capsules and eventually, buckling of the elastic membrane shell. This buckling deformation can be attributed to the capillary force arising when the encapsulated water escapes through the nanopores of the membrane. ${ }^{34}$ It should be noticed that the shell did not burst, even after several hours.

On the other hand, once the capsules were brought in contact with a filter paper, an instantaneous negative pressure was created inside the core, due to the suction pressure exerted by the filter paper, tending to drain the internal water from the capsules. When the water pressure in the core dropped below the vapour pressure at the ambient temperature, a capillary-induced cavitation occurred, leading to the formation of a vapour bubble in the core (Movie 1 in the supplementary material S6). However, the growing bubble could not fill up the entire space of the core since a thin layer of $\mathrm{K}_{2} \mathrm{CO}_{3}$ solution remained between the shell and the bubble due to retention of $\mathrm{K}^{+}$ and $\mathrm{HCO}_{3}{ }^{-}$ions by the shell membrane and build-up of an osmotic pressure gradient which opposed the induced capillary pressure (Figure s.3). The volume of the remaining inner phase solution can be estimated from a force balance between the capillary force and the osmotic pressure gradient at equilibrium. The bubble reached the equilibrium size very quickly, as shown in the video.

Capsules with a cavitation-formed vapour bubble, trapped inside the shell, were collected and stored in a sealed container to equilibrate the vapour pressure on both sides of the shell and prevent evaporation of water from the core. Over a period of one year, the capsules kept their mechanical integrity and there was only a slight change in their size. The $15 \mathrm{wt} \%$ and $5 \mathrm{wt} \%$ 
$\mathrm{K}_{2} \mathrm{CO}_{3}$ capsules before and after capillary-induced cavitation are shown in Figures 3e and 3f and $3 g$ and $3 h$, respectively. The same behaviour was observed for $30 \mathrm{wt} \% \mathrm{~K}_{2} \mathrm{CO}_{3}$ capsules. Further investigation is needed to fully understand the process of capillary-induced cavitation, which is beyond the scope of the current work.

\section{Carbon capture by the capsules}
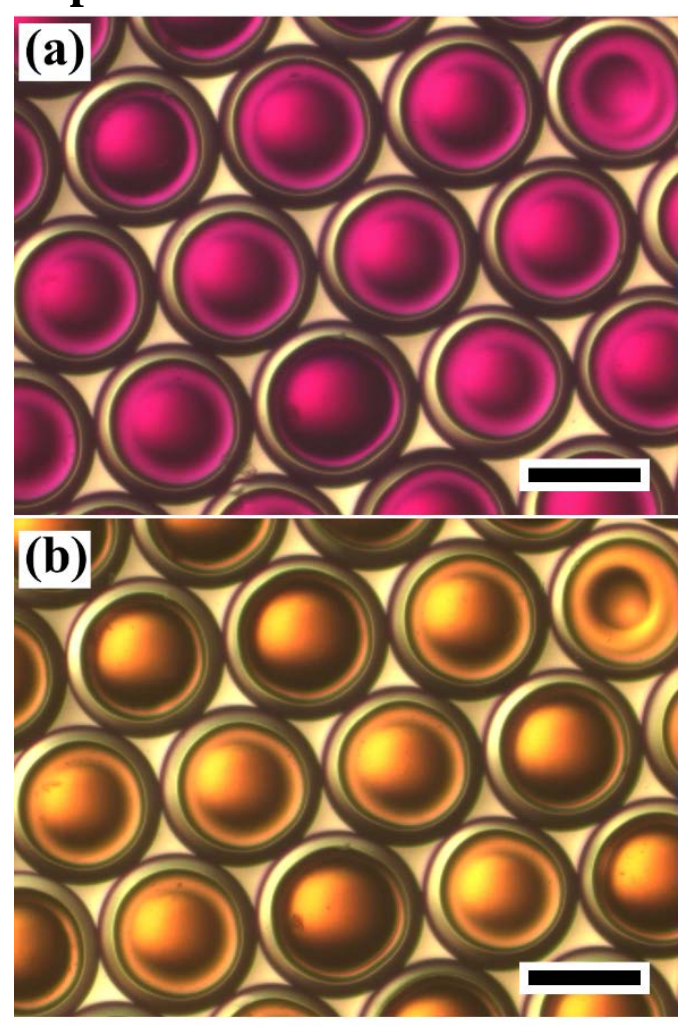

Figure 5. The capsules containing $5 \mathrm{wt} \% \mathrm{~K}_{2} \mathrm{CO}_{3}$ and m-cresol purple ( $\mathrm{pH}$ indicator) in the aqueous core: (a) prior to $\mathrm{CO}_{2}$ capture; (b) after $\mathrm{CO}_{2}$ uptake. The scale bar is $200 \mu \mathrm{m}$.

$\mathrm{K}_{2} \mathrm{CO}_{3}$ solutions have long been used for $\mathrm{CO}_{2}$ absorption. According to the stoichiometry of the reaction: $\mathrm{K}_{2} \mathrm{CO}_{3}+\mathrm{H}_{2} \mathrm{O}+\mathrm{CO}_{2} \rightarrow 2 \mathrm{KHCO}_{3}$, at $100 \% \mathrm{~K}_{2} \mathrm{CO}_{3}$ conversion the $\mathrm{CO}_{2}$ capture capacity of $30 \mathrm{wt} \%, 15 \mathrm{wt} \%$, and $5 \mathrm{wt} \% \mathrm{~K}_{2} \mathrm{CO}_{3}$ solution is $2.17 \mathrm{mmol} / \mathrm{g}, 1.08 \mathrm{mmol} / \mathrm{g}$, and 0.36 $\mathrm{mmol} / \mathrm{g}$, respectively, as compared to the solubility of $\mathrm{CO}_{2}$ in pure water of $0.0037 \mathrm{mmol} / \mathrm{g}$ at $25^{\circ} \mathrm{C}$. Although $\mathrm{CO}_{2}$ is absorbed only by $\mathrm{K}_{2} \mathrm{CO}_{3}$ solution and the shell material does not give 
any contribution to the amount of $\mathrm{CO}_{2}$ absorbed, the mass of the shell must be taken into account for calculation of the actual $\mathrm{CO}_{2}$ capture capacity of the capsule. The effect of the capsule shell will be considered by introducing the correction factor $\mathrm{C}_{\text {eff }}$, which is the ratio of the mass of the core solution to the mass of the entire capsule:

$$
C_{\text {eff }}=\frac{\rho_{c} D_{1}}{6 \rho_{s} t+\rho_{c} D_{1}}
$$

where $\rho_{\mathrm{c}}$ is the density of core solution, and $\rho_{\mathrm{s}}$ is the density of cured shell $\left(0.97 \mathrm{~g} \cdot \mathrm{cm}^{-3}\right)$. According to Eq. (2), for the capsules with the core diameter, $D_{1}$, of $200-400 \mu \mathrm{m}$ and the shell thickness, $\mathrm{t}$, of $10-30 \mu \mathrm{m}, \mathrm{C}_{\text {eff }}$ is $0.74-0.9$, which leads to the actual $\mathrm{CO}_{2}$ capture capacity of the $30 \mathrm{wt} \% \mathrm{~K}_{2} \mathrm{CO}_{3}$ capsules of $1.6-2.0 \mathrm{mmol} / \mathrm{g}$. Figure 5 shows the uptake of $\mathrm{CO}_{2}$ by the capsules containing $5 \mathrm{wt} \% \mathrm{~K}_{2} \mathrm{CO}_{3}$ and m-cresol purple, a dye indicator in its aqueous cores. A small amount of microcapsules was placed on a microscope slide and exposed to pure stream of $\mathrm{CO}_{2}$ introduced at a flow rate of $56 \mathrm{ml} / \mathrm{h}$ from a 1/4" PTFE tubing whose tip was placed 4-5 cm from the capsules (Movie 3 in S6). Prior to $\mathrm{CO}_{2}$ uptake, the core solution was purple (Figure 5a) because the $\mathrm{pH}$ of the core solution was 11.9. After exposure to $\mathrm{CO}_{2}$, the core liquid turned to yellow (Figure 5b and Movie 2 in S6) because the $\mathrm{pH}$ was reduced below 8 . The capsules can be regenerated by heating, e.g. in a microwave, which causes the reaction to proceed in the opposite direction and a pure stream of $\mathrm{CO}_{2}$ is released: $2 \mathrm{KHCO}_{3} \rightarrow \mathrm{CO}_{2}+\mathrm{K}_{2} \mathrm{CO}_{3}+\mathrm{H}_{2} \mathrm{O}$.

\section{Membrane shell characterisation}

The effects of different concentrations of DC 749 in the middle phase prior to polymerisation on the thermal and surface properties of the shell were also investigated. Three middle phase liquids containing 0, $0.5 \mathrm{wt} \%$, and $2 \mathrm{wt} \%$ DC 749 in Semicosil ${ }^{\circledR} 949$ were exposed to UV radiation to produce a thin solid membrane. The onset decomposition temperature of the shell material, i.e., 
the temperature at which $10 \%$ degradation occurs, measured using TGA was found to be 450 $460^{\circ} \mathrm{C}$ for all samples (Figure 6a). In addition, no endothermic peak was observed in DSC curves over the temperature range of $50-290^{\circ} \mathrm{C}$ (Figure 6b), since the initial temperature was higher than the glass transition temperature of the polymer and the melting point was not reached, implying high thermal stability of the shell material. Based on the DSC data, the specific heat capacity of the shell material, $\mathrm{C}_{\mathrm{s}}$, is $720-890 \mathrm{~J} \cdot \mathrm{Kg}^{-1} \cdot \mathrm{K}^{-1}$. In the $\mathrm{CO}_{2}$ desorption step, the energy is required to release $\mathrm{CO}_{2}$ from the saturated liquid. The heat (enthalpy) of absorption of $\mathrm{CO}_{2}$ only depends on the composition of the liquid phase and in unaffected by the presence of the shell. However, the energy consumption for heating up the capsules to the desired desorption temperature is affected by the heat capacity of both the liquid phase and the solid shell. The ratio of energy consumption for heating the entire capsule, $\mathrm{E}_{\text {capsule }}$, to that for heating the core liquid, $\mathrm{E}_{\text {core }}$, is given by:

$$
\frac{E_{\text {capsule }}}{E_{\text {core }}}=\frac{6 \rho_{\mathrm{s}} \mathrm{tC}_{\mathrm{s}}+\rho_{\mathrm{c}} \mathrm{D}_{1} \mathrm{C}_{\mathrm{c}}}{\rho_{\mathrm{c}} \mathrm{D}_{1} \mathrm{C}_{\mathrm{c}}}
$$

where $C_{c}$ is the specific heat capacity of the core solution, which varies between 3935 and 3014 $\mathrm{J} \cdot \mathrm{Kg}^{-1} \cdot \mathrm{K}^{-1}$ in the $\mathrm{K}_{2} \mathrm{CO}_{3}$ concentration range of 5-30 wt\%. For the capsules with $\mathrm{D}_{1}$ of 200-400 $\mu \mathrm{m}$ and a value of $\mathrm{t}$ of $10-30 \mu \mathrm{m}, \mathrm{E}_{\text {capsule }} / \mathrm{E}_{\text {core }}$ is $1.02-1.2$.

The FTIR spectra of the samples are presented in Figure 6c. The peaks at $2970 \mathrm{~cm}^{-1}$ and 1010 $\mathrm{cm}^{-1}$ can be attributed to stretching vibration of $\mathrm{C}-\mathrm{H}$ and $\mathrm{Si}-\mathrm{O}$ bonds, respectively. The peaks at $1260 \mathrm{~cm}^{-1}$ and $788 \mathrm{~cm}^{-1}$ correspond to bending and stretching vibration of $\mathrm{Si}-\mathrm{CH}_{3}$, respectively. There is no difference in FTIR spectra between the samples, which means that the presence of DC 749 in Semicosil ${ }^{\circledR} 949$ in the amounts of up to 2 wt\% does not have any impact on the shell properties. Therefore, a prolonged curing time for 2 wt\% DC 749 shell was most likely caused 
by accumulation of the stabiliser at the outer interface and the reduced intensity of the incident UV light.

\section{Long-term production of double emulsion}

A long-term stability of the drop formation process over a period of $50 \mathrm{~min}$ is presented in Figure 7 and Figure s.4. For double emulsion containing $30 \mathrm{wt} \% \mathrm{~K}_{2} \mathrm{CO}_{3}$ in the inner aqueous phase, a slight reduction in $\mathrm{D}_{2}$ was observed over the entire period with the maximum deviation of $2.1 \%$ from the initial $\mathrm{D}_{2}$ value of $372 \mu \mathrm{m}$ (Figure 7). On the other hand, there was a slight reduction in $\mathrm{D}_{1}$ followed by a slight increase, with the maximum deviation of 3.3\%. For double emulsion with $15 \mathrm{wt} \% \mathrm{~K}_{2} \mathrm{CO}_{3}$ in the core, the variations of $\mathrm{D}_{2}$ and $\mathrm{D}_{1}$ followed very similar pattern with the maximum deviation of $4.3 \%$ and $4.1 \%$. For double emulsion with $5 \mathrm{wt} \% \mathrm{~K}_{2} \mathrm{CO}_{3}$ in the core, the drop size variations were negligible with the maximum deviation of $0.5 \%$ and $1 \%$ for $\mathrm{D}_{2}$ and $\mathrm{D}_{1}$. 

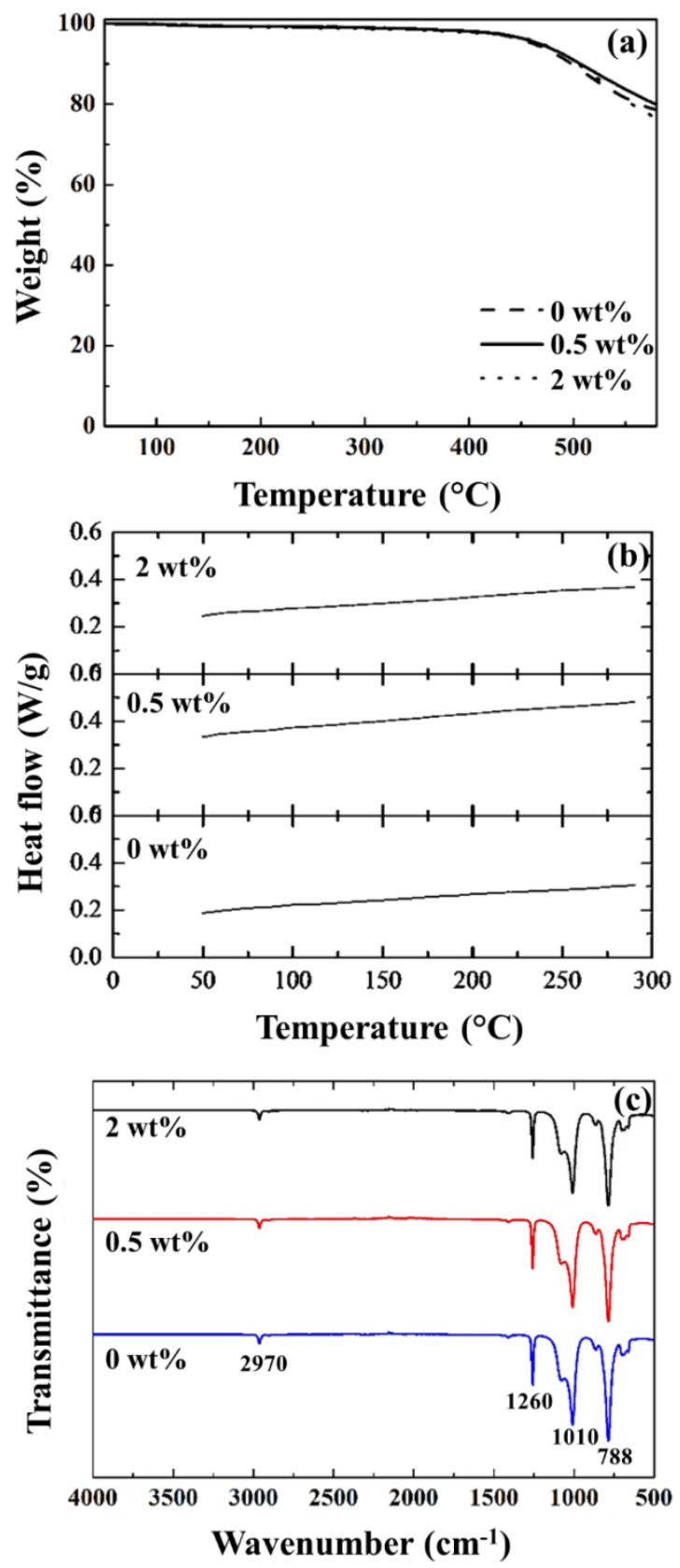

Figure 6. Characterisation of the shell membrane produced using different amounts of DC 749 in the middle phase: (a) TGA curves over the temperature range of $50-600^{\circ} \mathrm{C}$ at a ramp rate of $10^{\circ} \mathrm{C} / \mathrm{min}$ and under nitrogen flow; (b) DSC curves over the temperature range of 50$290^{\circ} \mathrm{C}$ at a ramp rate of $10^{\circ} \mathrm{C} / \mathrm{min}$ and under nitrogen flow; (c) FTIR spectra. 


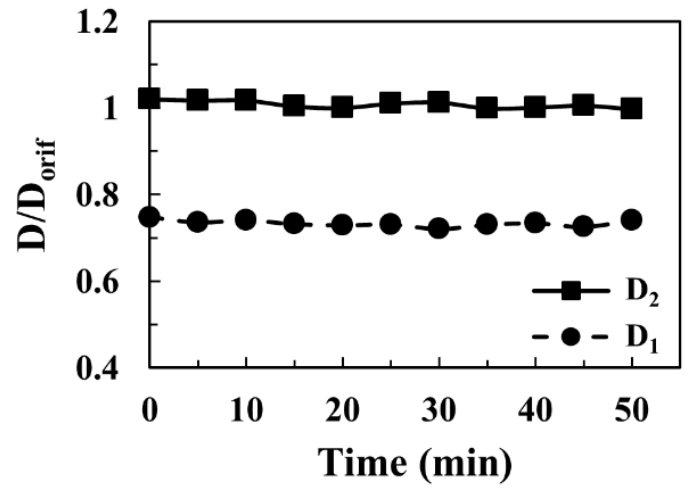

Figure 7. The variations of the size of inner and outer drops in the glass capillary microfluidic device over $50 \mathrm{~min}$. Inner phase: $30 \mathrm{wt} \% \mathrm{~K}_{2} \mathrm{CO}_{3}$ in water, middle phase: $0.5 \mathrm{wt} \%$ DC 749 in Semicosil $^{\circledR}$ 949, outer phase: 0.5 wt $\%$ PF-127 and $70 \mathrm{wt} \%$ glycerol in water. $\mathrm{D}_{\text {orif }}=365 \mu \mathrm{m}$. 


\section{CONCLUSIONS}

In this work, monodispersed gas-permeable microcapsules have been developed for gas capture and sensing consisting of elastic polymer shells of tuneable size and thickness and $\mathrm{pH}$-sensitive, gas selective liquid cores. $\mathrm{W}_{1} / \mathrm{O} / \mathrm{W}_{2}$ double emulsion drops of core-shell structure were generated in a glass capillary device and then the middle phase was polymerised on-the-fly using a UV-A light source. The effect of osmotic stress was investigated by developing an analytical model, capable of predicting the equilibrium size of the capsules based on the shell properties and the osmolarity of the storage solution and inner fluid. The model showed good agreement with the experimental data. The encapsulation efficiency of the core liquid of $100 \%$ has been achieved using 0.5-2 wt\% DC 749 stabiliser in the middle phase. The choice of water-soluble stabiliser in the outer phase was critical due to its potential $\mathrm{pH}$-triggered sedimentation that could lead to blockage of the device. The presence of $0.5 \mathrm{wt} \% \mathrm{PF}-127$ in the outer phase was found to provide sufficient long-term drop formation stability for 5-30 wt\% K2CO3 core solutions.

The minimum energy density and UV light irradiance needed for complete shell polymerisation were $2 \mathrm{~J} \cdot \mathrm{cm}^{-2}$ and $13.8 \mathrm{~mW} \cdot \mathrm{cm}^{-2}$, respectively, which corresponded to an exposure time of less than 3 min. The curing time after UV exposure for the capsules with $0.5 \mathrm{wt} \%$ DC 749 in the middle phase was 30-40 min. Longer curing times were needed for the higher DC 749 concentrations in the middle phase. A capillary-pressure-induced cavitation was observed once the capsules were in contact with a filter paper, which resulted in creation of a vapour bubble in the core surrounding by a layer of highly concentrated salt solution held in the core by an osmotic pressure gradient that acted against the induced capillary pressure. 
The capsules containing $\mathrm{K}_{2} \mathrm{CO}_{3}$ in the inner phase were capable of absorbing $\mathrm{CO}_{2}$ and the $\mathrm{CO}_{2}$ capture capacity of the $30 \mathrm{wt} \% \mathrm{~K}_{2} \mathrm{CO}_{3}$ capsules was $1.6-2 \mathrm{mmol} / \mathrm{g}$, depending on their size and shell thickness. The shell membrane was thermally stable up to $450-460^{\circ} \mathrm{C}$, implying that the capsules were suitable for applications at high operating temperatures, such as post-combustion $\mathrm{CO}_{2}$ capture. The fabrication method presented here is general and can be used to encapsulate any other liquid which is compatible with the shell material.

\section{ASSOCIATED CONTENT}

Supporting Information. Analytical model for prediction of the capsule morphology under osmotic stress (S1), images of the vials containing the capsules polymerised under different conditions (S2), schematic representation of the capillary-induced cavitation effect (S3), the data for long-term drop generation stability (S4) and $\mathrm{K}_{2} \mathrm{CO}_{3}$ shell permeability tests (S5), and the movies showing the capillary-induced cavitation effect and the uptake of $\mathrm{CO}_{2}$ by the capsules (S6). This material is available free of charge via the Internet at http://pubs.acs.org.

\section{AUTHOR INFORMATION}

\section{Corresponding Author}

*Corresponding author. Tel: +441509222518; E-mail address: g.vladisavljevic@lboro.ac.uk (G.T. Vladisavljević).

*Corresponding author: E-mail address: s.nabavi@cranfield.ac.uk (A.S. Nabavi).

\section{Notes}

The authors declare no competing financial interest. 


\section{ACKNOWLEDGMENT}

The authors gratefully acknowledge the financial support for this work from the EPSRC grant

EP/HO29923/1. The authors also thank Mr Shaun Fowler, Mr Ekanem E. Ekanem, and Dr Konstantin Loponov for their help and support during the entire experimental work.

\section{REFERENCES}

(1) Comiskey, B.; Albert, J. D.; Yoshizawa, H.; Jacobson, J. An Electrophoretic Ink for AllPrinted Reflective Electronic Displays. Nature 1998, 394, 253-255.

(2) Kim Y. J.; Sim, H. H.; Choi H. J.; Yoon, Y. S. Fabrication and Characterization of CoreShell Structured Black Pigment Particles for Electrophoretic Display. J. Nanosci. Nanotechnol. 2013, 13, 4279-4282.

(3) Lee, H.; Choi, C. H.; Abbaspourrad, A.; Wesner, C.; Caggioni, M.; Zhu, T. Weitz, D. A. Encapsulation and Enhanced Retention of Fragrance in Polymer Microcapsules. ACS Appl. Mater. Interfaces 2016, 8, 4007-4013.

(4) Shang, L.; Cheng, Y.; Wang, J.; Yu, Y.; Zhao, Y.; Chen, Y. Gu, Z. Osmotic PressureTriggered Cavitation in Microcapsules. Lab Chip 2016, 16, 251-255.

(5) Lee, M. H.; Hribar, K. C.; Brugarolas, T.; Kamat, N. P.; Burdick, J. A.; Lee, D. Harnessing Interfacial Phenomena to Program the Release Properties of Hollow Microcapsules. Adv. Funct. Mater. 2012, 22, 131-138.

(6) Abbaspourrad, A.; Datta, S. S.; Weitz, D. A. Controlling Release from pH-Responsive Microcapsules. Langmuir 2013, 29, 12697-12702. 
(7) Lorenzo-Lamosa, M. L.; Remuñán-López, C.; Vila-Jato, J. L. Alonso, M. J. Design of Microencapsulated Chitosan Microspheres for Colonic Drug Delivery. J. Control. Release 1998, 52, 109-118.

(8) Kim, B.; Lee, T. Y.; Abbaspourrad, A.; Kim, S. H. Perforated Microcapsules with Selective Permeability Created by Confined Phase Separation of Polymer Blends. Chem. Mater. 2014, 26, 7166-7171.

(9) Vilanova, N.; Rodríguez-Abreu, C.; Fernández-Nieves A.; Solans, C. Fabrication of Novel Silicone Capsules with Tunable Mechanical Properties by Microfluidic Techniques. ACS Appl. Mater. Interfaces 2013, 5, 5247-5252.

(10) Li, F.; Wang X.; Wu, D. Fabrication of Multifunctional Microcapsules Containing NEicosane Core and Zinc Oxide Shell for Low-Temperature Energy Storage, Photocatalysis, and Antibiosis. Energy Convers. Manag. 2015, 106, 873-885.

(11) Vericella, J. J.; Baker, S. E.; Stolaroff, J. K.; Duoss, E. B.; Hardin, J. O.; Lewicki, J.; Glogowski, E.; Floyd, W. C.; Valdez, C. A.; Smith, W. L.; Satcher, J. H.; Bourcier, W. L.; Spadaccini, C. M.; Lewis J. A.; Aines, R. D. Encapsulated Liquid Sorbents for Carbon Dioxide Capture. Nat. Commun. 2015, 6, 6124-6130.

(12) Tu, Y.; Peng, F.; Adawy, A.; Men, Y.; Abdelmohsen L. K. E. A.; Wilson, D. A. Mimicking the Cell: Bio-Inspired Functions of Supramolecular Assemblies. Chem. Rev. 2016, 116, 2023-2078.

(13) Vriezema, D. M.; Garcia, P. M. L.; Sancho Oltra, N.; Hatzakis, N. S., Kuiper, S. M., Nolte, R. J. M.; Rowan A. E.; Van Hest, J. C. M. Positional Assembly of Enzymes in 
Polymersome Nanoreactors for Cascade Reactions. Angew. Chem., Int. Ed. 2007, 46, 7378-7382.

(14) Zhang, W.; Zhao, S.; Rao, W.; Snyder, J.; Choi, J. K.; Wang, J.; Khan, I. A.; Saleh, N. B.; Mohler, P. J.; Yu, J.; Hund, T. J.; Tang, C.; He, X. A Novel Core-Shell Microcapsule for Encapsulation and 3D Culture of Embryonic Stem Cells. J. Mater. Chem. B 2013, 1, 1002-1009.

(15) Nakagawa, K.; Iwamoto, S.; Nakajima, M.; Shono, A.; Satoh, K. Emulsification Using Gelatin and Surfactant-Free Coacervate Microencapsulation. J. Colloid Interface Sci. 2004, 278, 198-205.

(16) Han, J. H.; Koo, B. M.; Kim, J. W.; Suh, K. D. A Facile Approach to Synthesize Uniform Hydrogel Shells with Controllable Loading and Releasing Properties. Chem. Commun. 2008, 8, 984-986.

(17) Donath, E.; Sukhorukov, G. B.; Caruso, F.; Davis, S. A. Möhwald, H. Novel Hollow Polymer Shells by Colloid-Templated Assembly of Polyelectrolytes. Angew. Chem., Int. Ed. 1998, 37, 2201-2205.

(18) Dowding, P. J.; Atkin, R.; Vincent, B.; Bouillot, P. Oil Core-Polymer Shell Microcapsules Prepared by Internal Phase Separation from Emulsion Droplets. I. Characterization and Release Rates for Microcapsules with Polystyrene Shells. Langmuir 2004, 20, 11374-11379.

(19) Mathiowitz, E.; Bernstein, H.; Giannos, S.; Dor, P.; Turek, T.; Langer, R. Polyanhydride Microspheres. IV. Morphology and Characterization of Systems Made by Spray Drying. J. Appl. Polym. Sci. 1992, 45, 125-134. 
(20) Nisisako, T.; Hatsuzawa, T. Microfluidic Fabrication of Oil-Filled Polymeric Microcapsules with Independently Controllable Size and Shell Thickness via Janus to Core-Shell Evolution of Biphasic Droplets. Sens. Actuators, B 2016, 223, 209-216.

(21) Utada, A. S.; Lorenceau, E.; Link, D. R.; Kaplan, P. D.; Stone, H. A.; Weitz, D. A. Monodisperse Double Emulsions Generated from a Microcapillary Device. Science 2005, 308, 537-541.

(22) Pannacci, N.; Bruus, H.; Bartolo, D.; Etchart, I.; Lockhart, T.; Hennequin, Y.; Willaime, H.; Tabeling, P. Equilibrium and Nonequilibrium States in Microfluidic Double Emulsions. Phys. Rev. Lett. 2008, 101, 164502-164505.

(23) Nisisako, T.; Okushima S.; Torii, T. Controlled Formulation of Monodisperse Double Emulsions in a Multiple-Phase Microfluidic System. Soft Matter 2005, 1, 23-27.

(24) Chang, Z.; Serra, C. A.; Bouquey, M.; Prat, L.; Hadziioannou, G. Co-Axial Capillaries Microfluidic Device for Synthesizing Size- and Morphology-Controlled Polymer CorePolymer Shell Particles. Lab Chip 2009, 9, 3007-3011.

(25) Vladisavljević, G. T.; Shahmohamadi, H.; Das, D. B.; Ekanem, E. E.; Tauanov, Z.; Sharma, L. Glass Capillary Microfluidics for Production of Monodispersed Poly (DlLactic Acid) and Polycaprolactone Microparticles: Experiments and Numerical Simulations. J. Colloid Interface Sci. 2014, 418, 163-70.

(26) Nabavi, S. A.; Vladisavljević, G. T.; Gu, S.; Ekanem, E. E. Double Emulsion Production in Glass Capillary Microfluidic Device: Parametric Investigation of Droplet Generation Behaviour. Chem. Eng. Sci. 2015, 130, 183-196. 
(27) Nabavi, S. A.; Gu, S.; Vladisavljević, G. T.; Ekanem, E. E. Dynamics of Double Emulsion Break-up in Three Phase Glass Capillary Microfluidic Devices. J. Colloid Interface Sci. 2015, 450, 279-287.

(28) da Silva, E. F.; Booth, A. M. Emissions from Postcombustion CO2 Capture Plants. Environ. Sci. Technol. 2013, 47, 659-660.

(29) Akagi, S. K.; Yokelson, R. J.; Wiedinmyer, C.; Alvarado, M. J.; Reid, J. S.; Karl, T.; Crounse, J. D.; Wennberg, P. O. Emission Factors for Open and Domestic Biomass Burning for Use in Atmospheric Models. Atmos. Chem. Phys. 2011, 11, 4039-4072.

(30) Hughes, E.; Maan, A. A.; Acquistapace, S.; Burbidge, A.; Johns, M. L.; Gunes, D. Z., Clausen, P.; Syrbe, A.; Hugo, J.; Schroen, K.; Miralles, V.; Atkins, T.; Gray, R.; Homewood, P.; Zick, K. Microfluidic Preparation and Self Diffusion PFG-NMR Analysis of Monodisperse Water-in-Oil-in-Water Double Emulsions. J. Colloid Interface Sci. 2013, 389, 147-156.

(31) Shirk, K.; Steiner, C.; Kim, J. W.; Marquez; M.; Martinez, C. J. Assembly of Colloidal Silica Crystals inside Double Emulsion Drops. Langmuir 2013, 29, 11849-11857.

(32) Tu, F.; Lee, D. Controlling the Stability and Size of Double-Emulsion-Templated Poly(lactic-Co-Glycolic) Acid Microcapsules. Langmuir 2012, 28, 9944-9952.

(33) Hassan, C. M.; Peppas, N. A. Structure and Applications of Poly (Vinyl Alcohol) Hydrogels Produced by Conventional Crosslinking or by Freezing / Thawing Methods. Adv. Polym. Sci. 2000, 153, 37-65. 
(34) Quilliet, C.; Zoldesi, C.; Riera, C.; Van Blaaderen, A.; Imhof, A. Anisotropic Colloids through Non-Trivial Buckling. Eur. Phys. J. E 2008, 27, 13-20.

\section{Graphical abstract}

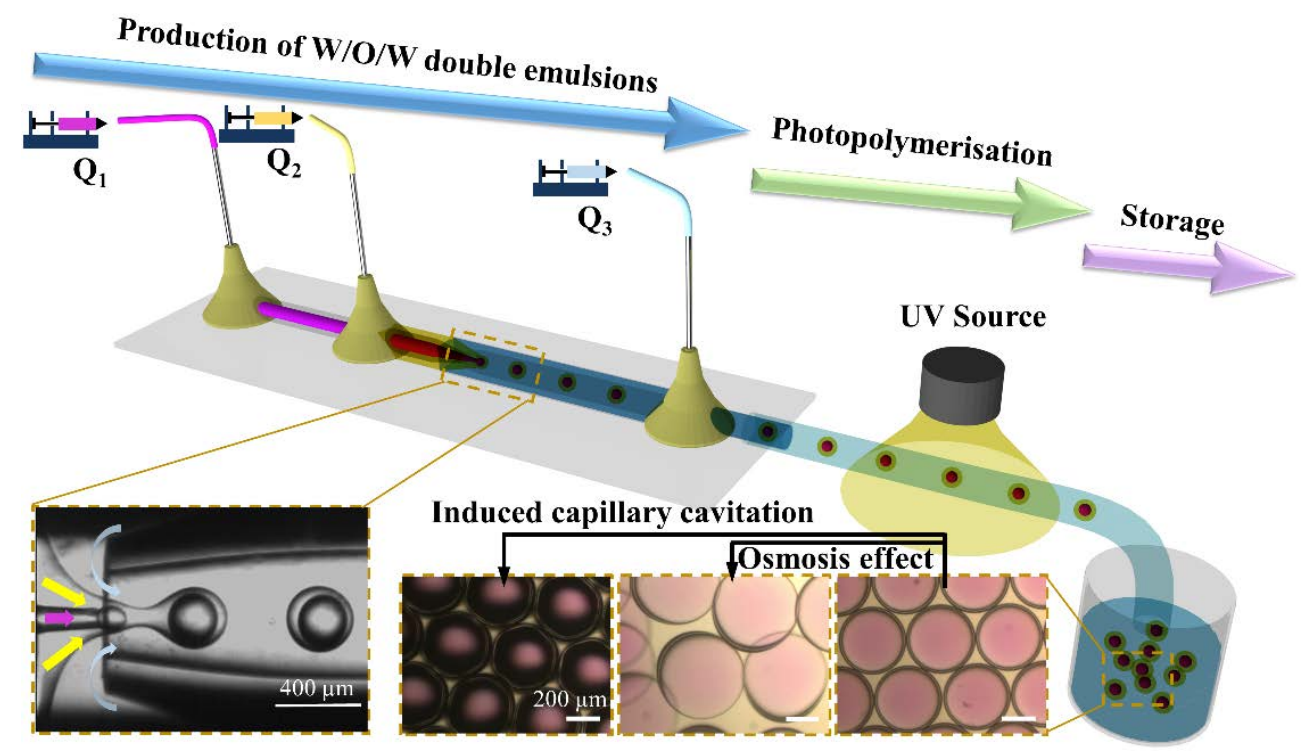

